\title{
Topology Generation and Analysis of the No Dead Time AC/DC Converter
}

\author{
Xinxin Zheng ${ }^{\dagger}$, Lan Xiao*, and Yangtian Tian* \\ $\dagger^{*}$ Jiangsu Key Laboratory of New Energy Generation and Power Conversion, \\ Nanjing University of Aeronautics and Astronautics, Jiangsu, China
}

\begin{abstract}
A novel topology generation method for the no dead-time three-phase AC/DC converter is proposed in this study. With this method, a series of no dead time topologies are generated and their operation principles are analyzed. The classic three-phase bridge $\mathrm{AC} / \mathrm{DC}$ converter can realize a bidirectional operation. However, dead-time should be inserted in the driving signals to avoid the shoot-through problem, which would cause additional harmonics. Compared with the bridge topology, the proposed topologies lack the shoot-through problem. Thus, dead time can be avoided. All of the no dead time three-phase AC/DC converters can realize bidirectional operation. The operating principles of the converters are analyzed in detail, and the corresponding control strategies are discussed. Comparisons of waveform distortion and efficiency among the converters are provided. Finally, 9 KW DSP-based principle prototypes are established and tested. Simulation and experimental results verify the theoretical analysis.
\end{abstract}

Keywords: Bidirectional work, No dead time, Shoot-through problem, Three-phase AC-DC converter, Zero-crossing distortion

\section{INTRODUCTION}

With the development of industries, the demand for three-phase $\mathrm{AC} / \mathrm{DC}$ converters is becoming more urgent. These converters can realize power conversion and power factor control and are widely applied in the field of wind power and electric vehicles [1]. Bridge topology is commonly utilized in three-phase AC/DC converters [2]. This topology can realize bidirectional operations and is easy to control. However, in each phase, the upper and lower power switches connect directly and may cause a shoot-through problem. Dead time must be inserted to the driving signals and additional harmonics should be introduced to increase the $\mathrm{AC}$ current THD and solve the abovementioned problem [3].

The harmonics caused by dead time can be reduced in two ways. One is through dead-time compensation [4], [5]. During the parameter search, the quality of the compensation is continuously assessed against the harmonic distortion of output currents. This method may complicate the control strategy of the converter. The other method is to improve the

Manuscript received Oct. 9, 2013; accepted Dec. 24, 2013

Recommended for publication by Associate Editor Honnyong Cha.

${ }^{\dagger}$ Corresponding Author: zhengxinin@gmail.com

Tel: +86-025-84892500, Fax: +86- 025-84892368, Nanjing University of Aeronautics and Astronautics

*Jiangsu Key Laboratory of New Energy Generation and Power Conversion, Nanjing University of Aeronautics and Astronautics, China topology. If the topology does not have a shoot-through problem, dead time is unnecessary. Dual-buck topology is a no dead time topology originally applied to single-phase inverters [6]. When the driving signals of the upper and lower power switches are complementary, the two buck circuits work together. This condition can be defined as full-cycle control. In this case, a bias current flows through the power switches. The driving signals should be shielded for half of the grid cycle to eliminate the bias current; this condition is defined as half-cycle control [7]. However, half-cycle control would lead to zero-crossing distortion [8].

Three-phase dual-buck inverters have been discussed recently [9]. These inverters are suitable for direct current control in the $d-q$ coordinate system and can obtain high PF (Power Factor). The dual-buck topology can also realize bidirectional operation. When the power flows from the $\mathrm{AC}$ side to the DC side, the converter operates as a rectifier and the topology can be viewed as dual-boost. For different power flowing directions, the half-cycle of the driving signals corresponds to different phase-sections of the grid voltage. The control strategy for the no dead time converter should also be considered to realize bidirectional operation.

For the abovementioned reasons, a topology generation method for no dead time three-phase AC/DC converters is proposed in this study. A series of no dead time topologies without the shoot-through problem is generated. All of the 


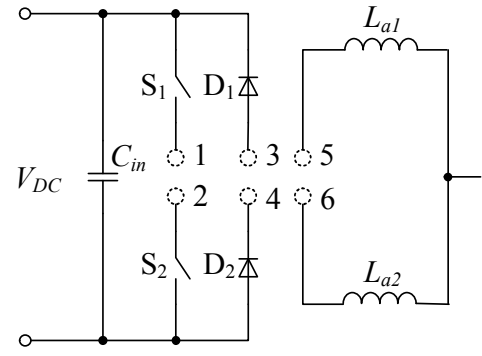

Fig. 1. No dead time structure of each phase.

topologies can realize bidirectional operation. The improved control strategies based on direct current control in the $d-q$ coordinate system are applied to the no dead time topologies to obtain high efficiency and low THD. The topology generation method is described in Section II. The operating principle of the no dead time topologies is described in Section III. The control strategies and the comparison of the no dead time topologies are introduced in Section IV. The simulation and experimental results of $9 \mathrm{~kW}$ no dead time three-phase AC/DC converters are presented to verify the theoretical analysis in Section V.

\section{TOPOLOGY GENERATION METHOD}

In the three-phase AC/DC converter, each phase arm has a similar operating principle. Thus, topology generation can consider only a single phase. The power switches of the upper and lower arm cannot connect directly to avoid the shoot-through problem. As shown in Fig. 1, inductors $L_{\mathrm{a} 1}$ and $L_{\mathrm{a} 2}$ have a filtering effect. The AC side filter inductor of the bridge topology can be replaced by $L_{\mathrm{a} 1}$ and $L_{\mathrm{a} 2}$. Each phase contains power switches, freewheeling diodes, and filter inductors. Six ports exist for connection and combination: Ports 1 to 6. Among them, Ports 1 and 2 cannot connect directly. Two types of combinations exist for Ports 1 to 4 . One is Port 1 connecting with Port 4 and Port 2 connecting with Port 3; this combination is defined as the $14 / 23$ combination. The other is Port 1 connecting with Port 3 and Port 2 connecting with Port 4 ; this combination is defined as the 13/24 combination. The two newly generated ports can connect with Ports 5 and 6 directly or through power switching devices.

The $14 / 23$ combination is equivalent to the topologies shown in Figs. 2(a) and 2(b). For this combination, the corresponding diode $\mathrm{D}_{2}$ or $\mathrm{D}_{1}$ freewheels after $\mathrm{S}_{1}$ or $\mathrm{S}_{2}$ is turned off. The current of inductance $L_{\mathrm{a} 1}$ and $L_{\mathrm{a} 2}$ would not mutate. Therefore, the two newly generated ports can not only connect with the inductance directly, but can also connect with the diode. Fig. 2(a) shows the dual-buck/boost topology. In Fig. 2(b), $\mathrm{D}_{\mathrm{aq}}$ participates in the freewheeling of the inductors. It connects the two newly generated ports 14 and 23. Thus, the topology can be defined as self- loop.

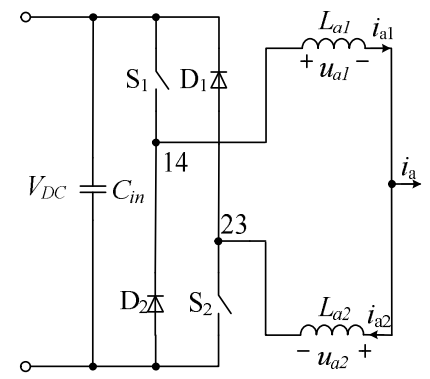

(a)

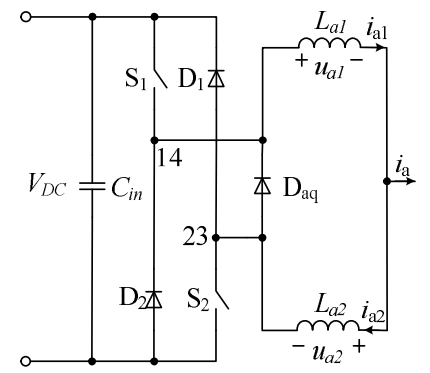

(b)



(c)

Fig. 2. Equivalent topology of the $14 / 23$ and $13 / 24$ combinations. (a) Dual-buck/boost topology. (b) Self-loop topology. (c) AC/DC topology with HFR.

The problem with the $13 / 24$ combination is that no freewheeling diode exists after $S_{1}$ or $S_{2}$ is turned off. This condition may lead to a voltage spike during inductor current mutation. A current freewheeling branch should thus be constructed. The 13/24 combination is equivalent to the topology shown in Fig. 2(c). High-frequency rectifiers (HFR) connect with the output of the upper and lower arms. $\mathrm{D}_{\mathrm{aq} 1}-\mathrm{D}_{\mathrm{aq} 4}$ form HFR. For example, after $\mathrm{S}_{1}$ is turned off, $L_{\mathrm{a} 1}$ freewheels through $\mathrm{D}_{\mathrm{aq} 2}$ to avoid the current mutation of the inductor. The reference direction of the current and voltage are shown in Fig. 2. Grid-side current $i_{\mathrm{a}}$ is the difference of inductor currents $i_{\mathrm{a} 1}$ and $i_{\mathrm{a} 2}$. When the grid voltage is in the positive half cycle and $i_{\mathrm{a}}$ is larger than 0 , the three types of converters operate as inverters. If $i_{\mathrm{a}}$ is lower than 0 , the three kinds of converters operate as rectifiers. For the converter with HFR shown in Fig. 2(c), $i_{\mathrm{a}}$ being lower than 0 when $i_{\mathrm{a} 1}$ is lower than $i_{\mathrm{a} 2}$ is possible. All the topologies can realize bidirectional operation. 


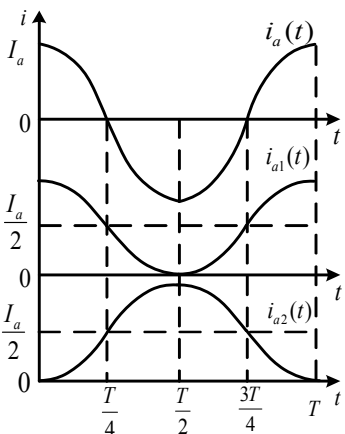

(a)

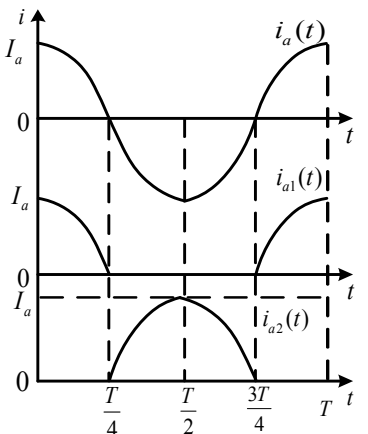

(b)
Fig. 3. Current waveforms of two situations. (a) Continuous inductor current. (b) Half-cycle inductor current.

\section{OPERATING PRINCIPLE}

\section{A. Dual-buck/boost Topology}

Two types of inductor currents exist for the dual-buck/boost topology. Under full-cycle control, the driving signals of $\mathrm{S}_{1}$ and $\mathrm{S}_{2}$ are complementary. Inductor currents that contain bias current always exist. Under half-cycle control, the driving signals of $S_{1}$ and $S_{2}$ are forced to be low for half of the grid cycle. The inductor currents would also last for half of the grid cycle. Fig. 3 presents the inductance current waveforms of the two situations.

The operation of the converter can be divided into two modes according to the direction of $i_{\mathrm{a}}$. In mode 1 , the direction of $i_{\mathrm{a}}$ is positive. In mode 2 , the direction of $i_{\mathrm{a}}$ is negative. With mode 1 as an example, Fig. 4 presents the probable working condition of mode 1 .

Bias currents exist under full-cycle control. As shown in Fig. 4(a), when $\mathrm{S}_{1}$ is turned on, the current of $L_{\mathrm{a} 2}$ freewheels through $\mathrm{D}_{1}, i_{\mathrm{a} 1}$ increases, and $u_{\mathrm{a} 1}$ is positive. The potential of $\operatorname{dot} \mathrm{A}$ is lower than that of $\operatorname{dot} \mathrm{P}$. Given that $\mathrm{D}_{1}$ conducts to ensure the current path, the potential of $\operatorname{dot} \mathrm{A}$ is also lower than that of dot F. At this time, $u_{\mathrm{a} 2}$ is negative and $i_{\mathrm{a} 2}$ decreases. When $\mathrm{S}_{1}$ is turned off, the current of $L_{\mathrm{a} 2}$ increases and flows through $\mathrm{S}_{2}$. As shown in Fig. 4(b), the switching and conduction losses of $\mathrm{S}_{2}$ cannot be avoided.

The current of $L_{\mathrm{a} 2}$ is 0 under half-cycle control. Fig. 4(c) shows that when $\mathrm{S}_{1}$ is turned on, the grid-side current equals $i_{\mathrm{a} 1}$ and $\mathrm{D}_{1}$ is turned off. When $\mathrm{S}_{1}$ is turned off, $\mathrm{S}_{2}$ is still turned off. Fig. 4(d) shows that no switching or conduction loss of $\mathrm{S}_{2}$ is observed during this period. Therefore, half-cycle control can obtain higher efficiency than full-cycle control.

The operating principle of mode 2 is similar. In one grid cycle, the full-cycle controlled inductor current of $L_{\mathrm{a} 1}$ and $L_{\mathrm{a} 2}$ can be expressed as

$$
\begin{aligned}
& i_{a 1}=\frac{I_{a}}{2} \cos \omega t+\frac{I_{a}}{2} \\
& i_{a 2}=-\frac{I_{a}}{2} \cos \omega t+\frac{I_{a}}{2}
\end{aligned}
$$



(a)

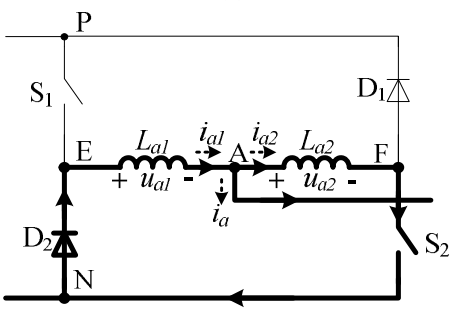

(b)



(c)

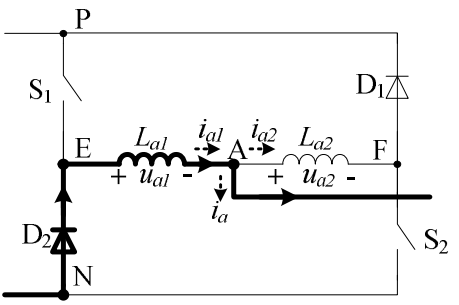

(d)

Fig. 4. Probable working condition of Mode 1. (a) $S_{1}$ on, $S_{2}$ off, and $D_{1}$ on. (b) $S_{1}$ off, $S_{2}$ on, and $D_{1}$ off. (c) $S_{1}$ on and $S_{2}$ off. (d) $\mathrm{S}_{1}$ off, $\mathrm{S}_{2}$ off, and $\mathrm{D}_{1}$ off.

The half-cycle controlled inductor current of $L_{\mathrm{a} 1}$ and $L_{\mathrm{a} 2}$ can be expressed as

$$
\begin{aligned}
& i_{a 1}= \begin{cases}I_{a} \cos \omega t & \text { (Mode 1) } \\
0 & (\text { Mode 2) }\end{cases} \\
& i_{a 2}= \begin{cases}0 & \text { (Mode 1) } \\
I_{a} \cos \omega t & \text { (Mode 2) }\end{cases}
\end{aligned}
$$

\section{B. Self-loop AC/DC Topology}

The operation of the self-loop AC/DC converter can also be divided into two modes. Fig. 5 presents the operating modes of the self-loop converter.

The currents of $L_{\mathrm{a} 1}$ and $L_{\mathrm{a} 2}$ are always continuous because of $\mathrm{D}_{\mathrm{aq}}$. When $\mathrm{S}_{1}$ is turned on similar to the full-cycle controlled dual-buck/boost converter, $i_{\mathrm{a} 1}$ increases and $i_{\mathrm{a} 2}$ decreases. This condition means that $i_{\mathrm{a}}$ also increases. When 


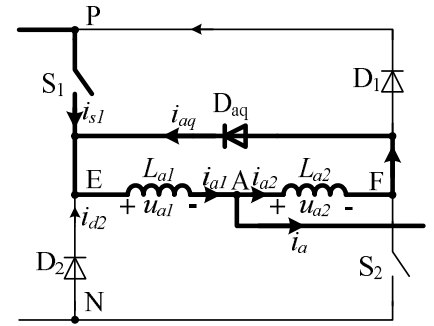

(a)

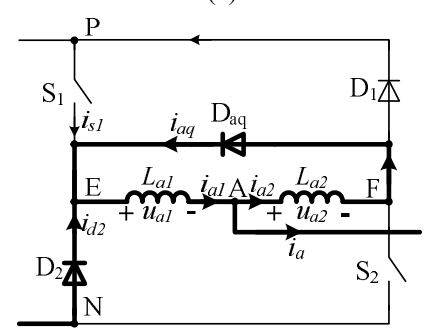

(b)

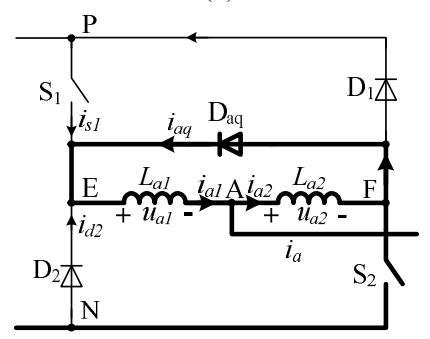

(c)

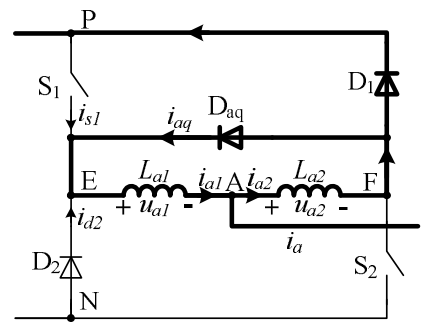

(d)

Fig. 5. Operating mode of the self-loop AC/DC converter. (a) $S_{1}$ on in mode 1. (b) $S_{1}$ off in mode 1. (c) $S_{2}$ on in mode 2. (d) $S_{2}$ off in mode 2.

$\mathrm{S}_{1}$ is turned off, the current of $L_{\mathrm{a} 2}$ still flows through $\mathrm{D}_{\mathrm{aq}} . i_{\mathrm{a} 2}$ has no relationship with the switching state of $\mathrm{S}_{2}$. Therefore, full-cycle control does not cause additional switching and conduction losses of $S_{2}$. However, additional conduction loss is caused by $\mathrm{D}_{\mathrm{aq}}$. The current of $\mathrm{D}_{\mathrm{aq}}$ can be expressed as

$$
\begin{cases}i_{a q}=i_{a 2}=i_{a 1}-i_{s 1} & S_{1} O N \\ i_{a q}=i_{a 2}=i_{a 1}-i_{d 2} & S_{1} O F F\end{cases}
$$

where $i_{\mathrm{s} 1}$ and $i_{\mathrm{d} 2}$ are the current flow through $\mathrm{S}_{1}$ and $\mathrm{D}_{2}$, respectively. The difference between the self-loop AC/DC converter and the dual-buck/boost converter is that $L_{\mathrm{a} 1}, L_{\mathrm{a} 2}$, and $\mathrm{D}_{\mathrm{aq}}$ of the self-loop topology can form a current loop. Although full-cycle control is applied, the current flow through $S_{1}$ and $S_{2}$ only lasts for half of the grid-cycle.

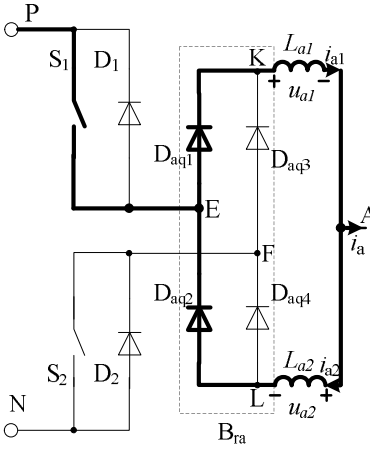

(a)



(c)

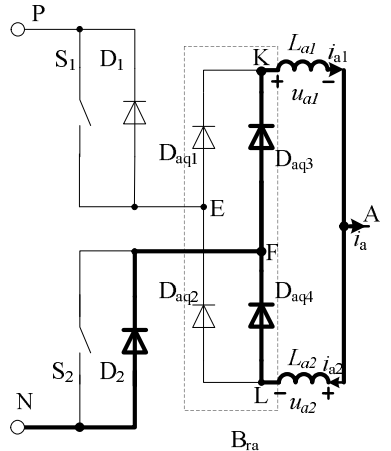

(b)

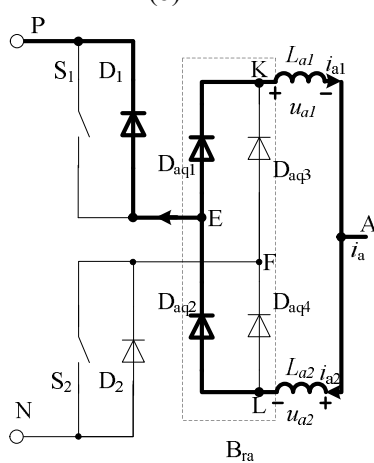

(d)
Fig. 6. Operating mode of the converter with HFR. (a) $S_{1}$ on in mode 1. (b) $S_{1}$ off in mode 1. (c) $S_{2}$ on in mode 2. (d) $S_{2}$ off in mode 2 .

\section{AC/DC Topology with HFR}

Fig. 6 presents the operating modes of the converter with HFR. The operating principle is similar to that of the self-loop AC/DC converter. $\mathrm{D}_{\mathrm{aq} 1}$ to $\mathrm{D}_{\mathrm{aq} 4}$ are the HFR diodes. They form a loop with $L_{\mathrm{a} 1}$ and $L_{\mathrm{a} 2}$ instead of $\mathrm{D}_{\mathrm{aq}}$. Although no current flows through $S_{2}$ when $S_{1}$ is turned off and $S_{2}$ is turned on, the loss of HFR diodes is high.

\section{CONTROL StRATEGIES AND THEIR COMPARISON}

\section{A. Control Strategies for the No Dead Time Converters}

The SVPWM control strategy is widely used in three-phase AC/DC converters for its precise control of the AC side current and high DC voltage utilization. A three-phase dual-buck/boost converter requires half-cycle control to obtain high efficiency. The control method is shown in Fig. 7. The actual circuit utilizes an LCL filter in the AC side to inhibit high-frequency harmonics [10]. $L_{\mathrm{a} 1}, L_{\mathrm{a} 2}$, $L_{\mathrm{b} 1}, L_{\mathrm{b} 2}, L_{\mathrm{c} 1}$, and $L_{\mathrm{c} 2}$ can be viewed as the converter-side inductors of the LCL filter. The part in the dashed box is half-cycle control. For full-cycle control, if the direction of active current set $i_{\mathrm{qg}}{ }^{*}$ is changed, the converter would change between the rectifier and inverter to realize a bidirectional operation. For half-cycle control, the direction of $i_{\mathrm{qg}}{ }^{*}$ and the half cycle shielding driving signals should both be changed. 




Fig. 7. SVPWM control method.

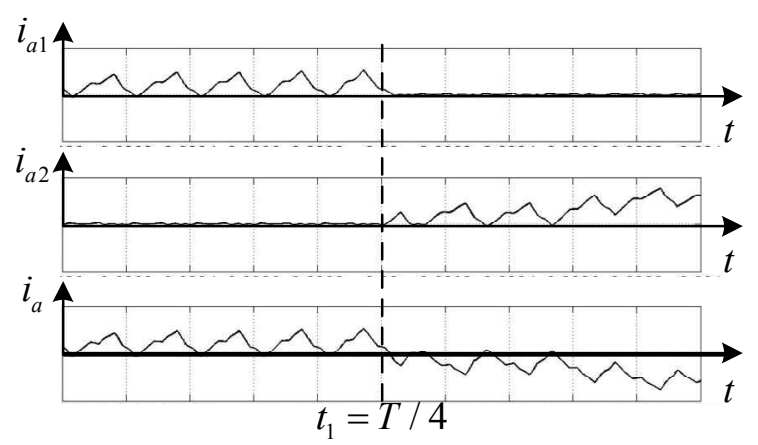

Fig. 8. High-frequency current ripple of inductance work switching.

With the arm of phase $a$ as an example, $i_{\mathrm{dg}}{ }^{*}$ is positive when the converter operates as an inverter. When $0 \leq i_{\mathrm{dg}}{ }^{*}$, the comparison signal $c_{\mathrm{mpl}}$ is at a high level. When phase voltage $v_{\mathrm{a}}$ is positive, the inverter converter-side current $i_{\mathrm{ac}}$ is also positive. The drive signal of $\mathrm{S}_{2}$ should be shielded. When $0 \leq$ $v_{\mathrm{a}}$, comparison signal $c_{\text {mpa }}$ is at a high level. For the XOR operation of $c_{\mathrm{mpa}}$ and $c_{\mathrm{mp} 1}$, the $\mathrm{S}_{2}$ shielding signal $c_{\mathrm{downa}}$ is at a low level. The drive signal of $\mathrm{S}_{2}$ is shielded after the AND operation with the drive signal of $\mathrm{S}_{2}$. The $\mathrm{S}_{1}$ shielding signal $c_{\text {up }}$ is the NOT operation of $c_{\text {downa }}$ and is at a high level. Thus, the drive signal of $\mathrm{S}_{1}$ would not be shielded. When $v_{\mathrm{a}}$ is negative, $c_{\text {up }}$ is at a low level and the drive signal of $S_{1}$ is shielded. When the converter operates as a rectifier, $i_{\mathrm{dg}}{ }^{*}$ is negative. For $0 \geq i_{\mathrm{dg}}{ }^{*}, c_{\mathrm{mp} 1}$ is at a low level. At this time, the shielding signal is opposite to the inverter mode.

However, a self-loop three-phase AC/DC converter and a three-phase AC/DC converter with HFR do not require half-cycle control. The control strategy can thus be simplified. The part in the dashed box can be left out. Except for no dead time, the strategy for the two types of converters is similar to that of a traditional three-phase bridge converter.

\section{B. Comparison of the No Dead Time Converters}

Half-cycle controlled dual-buck/boost converters can obtain high efficiency, but zero-crossing distortion is a serious problem. With time $t_{1}=\mathrm{T} / 4$ as an example, the current of $L_{\mathrm{a} 1}$ and $L_{\mathrm{a} 2}$ switches at this time. Thus, the high-frequency current ripple of $i_{\mathrm{a}}$ changes suddenly from positive to negative. The process is shown in Fig. 8.

The current ripple of $i_{\mathrm{a}}$ can be expressed as

$$
\Delta i_{a}=\frac{0.5\left(V_{D C}-e_{a}\right) D_{s} T_{s}}{L_{a 1}+L_{a g}}
$$

where $D_{\mathrm{s}}$ is the duty cycle. At the zero-crossing time of $i_{\mathrm{a}}$, the equivalent modulation wave of SVPWM can be expressed as

$$
u_{\text {mod }}=\frac{V_{D C}}{2}+\frac{3}{4} M V_{D C} \sin \left(\omega_{1} t+\frac{\pi}{2}\right) .
$$

At $t_{1}$ time, $D_{\mathrm{s}}$ equals 0.5 and $e_{\mathrm{a}}$ equals $0 . \Delta i_{\mathrm{a}}$ is high. Its effect on $i_{\mathrm{a}}$ cannot be ignored. Zero-crossing distortion is more serious in the half-cycle, SVPWM-controlled, three-phase dual-buck/boost converter than in the single-phase converter. SVPWM control requires coordinate transformation, and the three-phase currents influence each other. The current zero-crossing distortion of one phase would distort the other phases. Zero-crossing distortion thus reduces the quality of the current. The further improvement of the control strategy for the dual-buck/boost converter should also be considered.

Full-cycle controlled dual-buck/boost converters, self-loop AC/DC converters, and AC/DC converters with HFR do not exhibit zero-crossing distortion. However, additional losses may reduce the efficiency of the converters. Four types of losses exist: conduction loss of IGBT, conduction loss of the diode [11], switching loss of IGBT, and reverse recovery loss of the diode [12].

The mathematical model of IGBT and the diode can be expressed as

$$
U_{t v}=\frac{U_{r o n}-U_{o n}}{I_{N}} * I_{c o n}+U_{o n}
$$

where $U_{\mathrm{tv}}$ is the terminal voltage, $U_{\text {ron }}$ is the voltage drop at rated current $I_{\mathrm{N}}, U_{\text {on }}$ is the voltage drop at light load, and $I_{\text {con }}$ is the actual current of the power device. The conduction loss of IGBT and the diode can thus be expressed as

$$
P_{c l}=\frac{1}{T} \int_{0}^{T}\left(\frac{U_{r o n}-U_{o n}}{I_{N}} I_{c o n}{ }^{2} D_{s}+U_{o n} I_{c o n} D_{s}\right) d t .
$$

The switching loss of IGBT can be expressed as

$$
P_{s w}=\left(E_{s w(o n)}+E_{s w(o f f)}\right) f_{s} * \frac{2}{T I_{a}} \int_{0}^{T / 2} I_{c o n} d t
$$

where $E_{\mathrm{sw}(\mathrm{on})}$ and $E_{\mathrm{sw}(\mathrm{off})}$ are the turn-on and turn-off losses at a rated current, respectively. These values can be obtained from the datasheet. Reverse recovery loss can be expressed as

$$
P_{r e c}=E_{r e c} f_{s} * \frac{2}{T I_{a}} \int_{0}^{T / 2} I_{c o n} d t \text {. }
$$




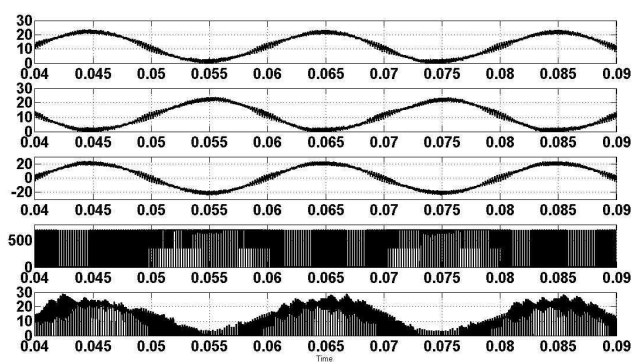

(a)

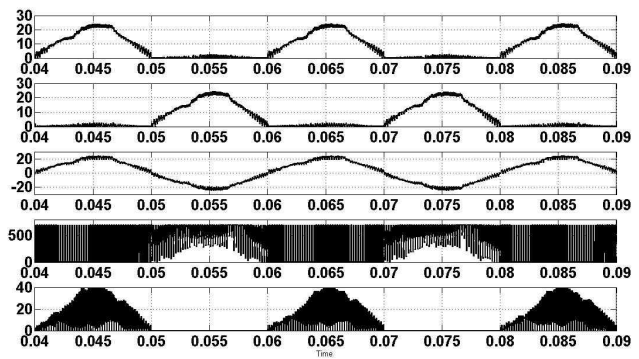

(b)

Fig. 9. Key waveforms of the dual-buck/boost AC/DC converter. (a) Full-cycle control. (b) Half-cycle control.

With mode 1 of the three topologies as an example, for the half-cycle controlled dual-buck/boost converter, $\mathrm{S}_{2}$ does not turn on and no additional conduction or switching loss of $\mathrm{S}_{2}$ occurs when $S_{1}$ is turned off. For the full-cycle controlled dual-buck/boost converter, $S_{2}$ turns on and an additional conduction or switching loss of $S_{2}$ occurs when $S_{1}$ is turned off. For the self-loop AC/DC converter, when $S_{1}$ is turned off and regardless of $\mathrm{S}_{2}$ being turned on, no additional conduction or switching loss of $\mathrm{S}_{2}$ occurs. However, an additional conduction loss of $\mathrm{D}_{\mathrm{aq}}$ occurs. For the AC/DC converter with HFR, additional conduction and reverse recovery losses of $D_{a q 1}$ to $D_{a q 4}$ occur.

\section{SIMULATION AND EXPERIMENTAL RESULTS}

The three types of no dead time, three-phase, AC/DC converters are simulated with the simulation software MATLAB/Simulink to verify the theoretical analysis. The DC-link voltage is $700 \mathrm{~V}$, and the AC side is connected with a $220 / 380 \mathrm{~V} / 50 \mathrm{~Hz}$ three-phase grid. For the inverter operation, the given active power $P$ is $9 \mathrm{~kW}$ and reactive power $Q$ is 0 . For the rectifier operation, the given active power $P$ is $-9 \mathrm{~kW}$ and reactive power $Q$ is 0 .

Fig. 9 presents the simulation result of the dual-buck/boost AC/DC converter. The waveforms are inductance currents $i_{\mathrm{a} 1}$ and $i_{\mathrm{a} 2}$, AC current $i_{\mathrm{a}}$, voltage of $\mathrm{S}_{1}$, and current of $\mathrm{S}_{1}$. Fig. 9(a) corresponds to full-cycle control. $i_{\mathrm{a} 1}$ and $i_{\mathrm{a} 2}$ have a DC bias, and the current flow through $S_{1}$ lasts for the full grid cycle; thus, high switching and conduction losses would occur. Fig. 9(b) corresponds to half-cycle control. The

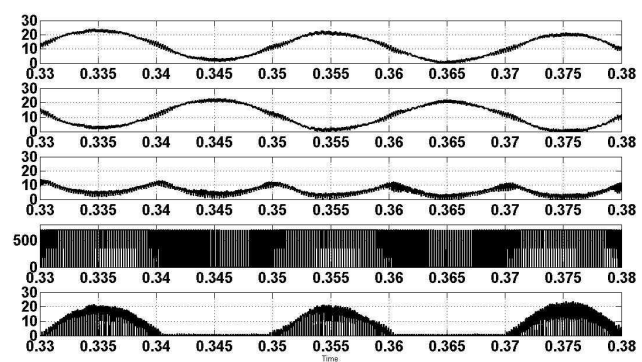

Fig. 10. Key waveforms of the self-loop AC/DC converter.

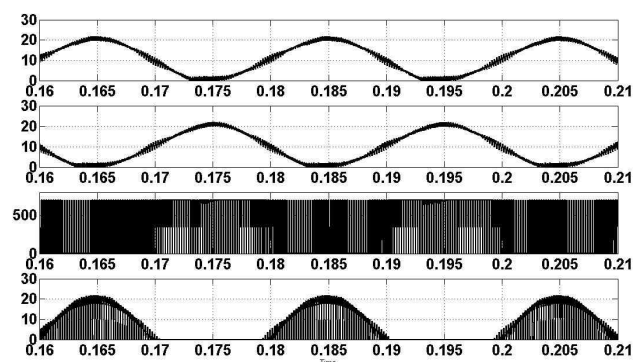

(a)

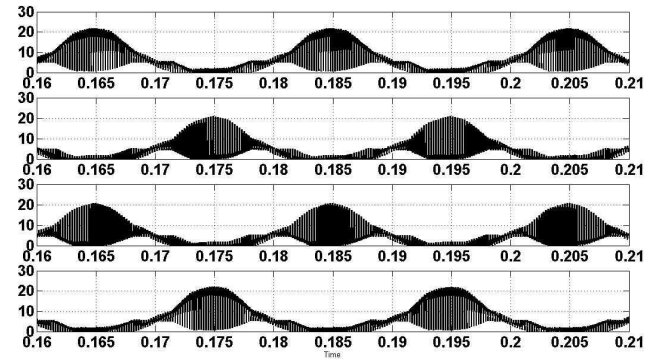

(b)

Fig. 11. Key waveforms of the AC/DC converter with HFR. (a) Waveforms of the inductance and power switch. (b) Waveforms of the HFR diodes.

driving signals only last for half of the grid cycle. Thus, the current of $S_{1}$ lasts for half of the grid cycle. Zero-crossing distortion occurs. Moreover, given the three-phase coordinate transformation, one phase distortion would affect the other two phases and would exacerbate the distortion.

Fig. 10 presents the simulation result of the self-loop AC/DC converter. The waveforms are inductance currents $i_{\mathrm{a} 1}$ and $i_{\mathrm{a} 2}$, current of diode $\mathrm{D}_{\mathrm{aq}}$, voltage of $\mathrm{S}_{1}$, and current of $\mathrm{S}_{1}$. Regardless of full-cycle or half-cycle control, the current of $\mathrm{S}_{1}$ only lasts for half of the grid cycle and the current of $L_{\mathrm{a} 1}$ and $L_{\mathrm{a} 2}$ are continuous. Zero-crossing distortion can thus be avoided. The current flow through $\mathrm{D}_{\mathrm{aq}}$ causes conduction loss, which would reduce the converter efficiency. However, the current value and the loss are low.

Fig. 11 presents the simulation result of the AC/DC converter with HFR. The waveforms in Fig. 11(a) are inductance currents $i_{\mathrm{a} 1}$ and $i_{\mathrm{a} 2}$, voltage of $\mathrm{S}_{1}$, and current of $\mathrm{S}_{1}$. $i_{\mathrm{a} 1}$ and $i_{\mathrm{a} 2}$ have a DC bias, but the current of $\mathrm{S}_{1}$ only lasts for half of the grid cycle. The switching and conduction losses of 




(a)



(b)

Fig. 12. Experimental results of the dual-buck/boost AC/DC converter. (a) Full-cycle control. (b) Half-cycle control.

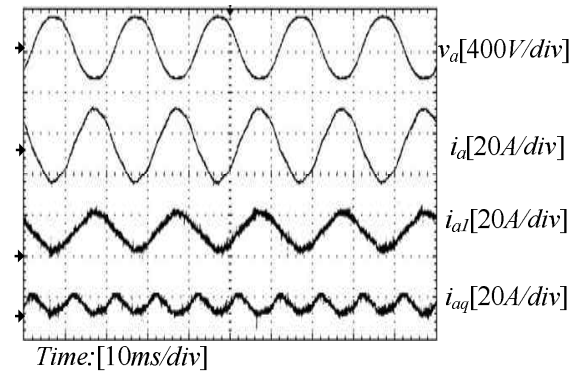

Fig. 13. Experimental results of the self-loop AC/DC converter.

$\mathrm{S}_{1}$ caused by a redundant driving signal can be avoided. However, additional conduction loss in the HFR diodes is inevitable. In Fig. 11(b), the waveforms are the currents of HFR diodes $\mathrm{D}_{\mathrm{aq} 1}$ to $\mathrm{D}_{\mathrm{aq} 4}$. $i_{\mathrm{a} 1}$ is the sum of the current flow through $\mathrm{D}_{\mathrm{aq} 1}$ and $\mathrm{D}_{\mathrm{aq} 3}$. $i_{\mathrm{a} 2}$ is the sum of the current flow through $\mathrm{D}_{\mathrm{aq} 2}$ and $\mathrm{D}_{\mathrm{aq} 4}$. The current causes a high conduction loss of $\mathrm{D}_{\mathrm{aq} 1}$ to $\mathrm{D}_{\mathrm{aq} 4}$.

Compared with the self-loop three-phase AC/DC converter, the AC/DC converter with HFR has more power devices and exhibits higher power loss. The advantages of these two converters are similar. Hence, the $9 \mathrm{~kW}$ self-loop AC/DC converter and the dual-buck/boost AC/DC converter are built to verify the analysis with the same parameters as in the simulation. A $9 \mathrm{~kW}$ traditional-bridge three-phase converter is also built for the comparison.

Fig. 12 presents the experimental results of the full-cycle and half-cycle controlled dual buck/boost AC/DC converter in terms of rectifier operation. The waveforms are grid voltage, AC-side current, and inductance currents $i_{\mathrm{a} 1}$ and $i_{\mathrm{a} 2}$. The waveform quality of full-cycle control is much higher than that of half-cycle control. Fig. 13 presents the

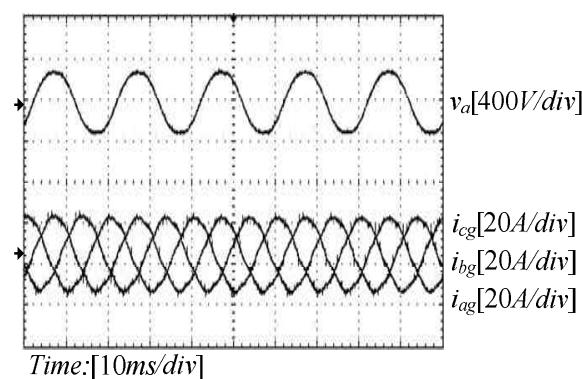

(a)

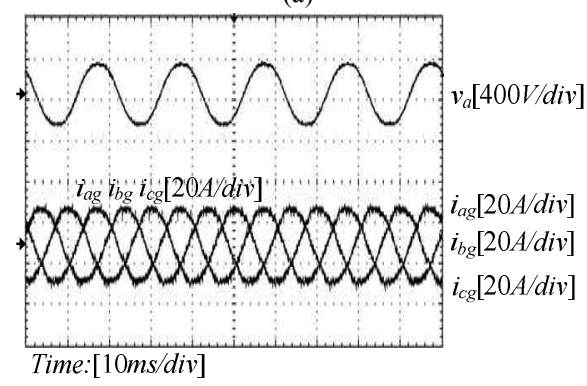

(b)

Fig. 14. AC side voltage and current. (a) Traditional bridge converter. (b) Self-loop converter.

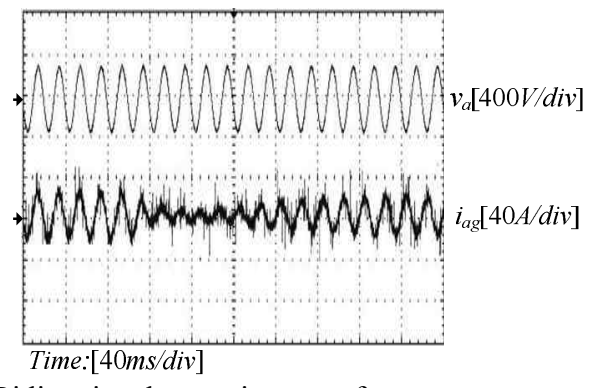

Fig. 15. Bidirectional operation waveform.

experimental results of the self-loop $\mathrm{AC} / \mathrm{DC}$ converter in terms of rectifier operation. The waveforms are grid voltage, AC-side current, inductance current $i_{\mathrm{a} 1}$, and the current of diode $\mathrm{D}_{\mathrm{aq}}$. These waveforms are consistent with those in the simulation results.

Fig. 14 presents the voltage and current of traditional-bridge and self-loop converters when they operate as inverters. Table I presents the comparison data of these topologies. The efficiency of the self-loop AC/DC converter is higher than that of the full-cycle controlled dual-buck/boost $\mathrm{AC} / \mathrm{DC}$ converter because the conduction loss of the diodes is lower than the switching and conduction losses of the power switches. The THD of the self-loop AC/DC converter is lower than that of the half-cycle controlled dual-buck/boost $\mathrm{AC} / \mathrm{DC}$ converter because no zero-crossing distortion occurred in the former.

Fig. 15 shows the bidirectional operation of the self-loop three-phase converter. The current should be controlled to change gradually to avoid current impact. When the converter changes from rectifier to inverter, no current rush occurs and the response time is short. 
TABLE I

COMPARISON OF EFFICIENCY AND THD

\begin{tabular}{|c|c|c|}
\hline & $\begin{array}{c}\text { Efficiency } \\
(\mathbf{\%})\end{array}$ & $\begin{array}{c}\text { THD } \\
(\%)\end{array}$ \\
\hline Traditional-bridge AC/DC converter & 98.35 & 6.0 \\
\hline $\begin{array}{c}\text { Full-cycle controlled dual-buck/boost } \\
\text { AC/DC converter }\end{array}$ & 94.38 & 3.2 \\
\hline $\begin{array}{c}\text { Half-cycle controlled dual-buck/boost } \\
\text { AC/DC converter }\end{array}$ & 98.41 & 7.9 \\
\hline Self-loop AC/DC converter & 98.26 & 3.1 \\
\hline
\end{tabular}

\section{CONCLUSIONS}

A topology generation method for the no dead zone AC/DC converter was developed in this study. Three topologies, including a dual-buck/boost converter, were generated. No shoot-through problem was observed in the converters, and bidirectional operation was realized. The low-frequency harmonics and the filter specifications can be reduced. The proposed no dead time converters have the following characteristics.

1) The dual-buck/boost converter requires half-cycle control to achieve high efficiency. The reverse recovery loss of the external diodes in this converter is less than that of the integrated diodes in the classic bridge converter. However, zero-crossing distortion may reduce the THD of the half-cycle controlled dual-buck/boost converter.

2) The self-loop $\mathrm{AC} / \mathrm{DC}$ converter does not require half-cycle control and has no zero-crossing distortion. However, the additional diodes cause additional loss, and the efficiency of this converter may be less than that of the half-cycle controlled dual-buck/boost converter. The self-loop AC/DC converter has one more diode than the classic bridge converter; nevertheless, their efficiencies have minimal difference.

3) The AC/DC converter with HFR also does not require half-cycle control. However, the number of additional diodes is more than that in the self-loop $\mathrm{AC} / \mathrm{DC}$ converter. The efficiency of the AC/DC converter with HFR is low.

\section{ACKNOWLEDGMENT}

The authors would like to acknowledge the support provided by the Jiangsu Provincial Cooperative Innovation Fund Prospective Joint Research Project (BY2012021), the National Natural Science Foundation (51377082), and the Jiangsu province university outstanding science and technology innovation team project.

\section{REFERENCES}

[1] X.-S. Pu, T. H. Nguyen, D.-C. Lee, K.-B. Lee, and J.-M. Kim, "Fault diagnosis of DC-Link capacitors in three-phase AC/DC PWM converters by online estimation of equivalent series resistance," IEEE Trans. Ind. Electron., Vol. 60, No. 4 , pp. 4118-4127, Sep. 2013.
[2] M. Hartmann, H. Ertl, and J. W. Kolar, "Current control of three-phase rectifier systems using three independent current controllers," IEEE Trans. Power Electron., Vol. 28, No. 8, pp. 3988-4000, Aug. 2013.

[3] G. Tan, Q. Deng, and Z. Liu, "An optimized SVPWM strategy for five-level active NPC (5L-ANPC) converter," IEEE Trans. Power Electron., Vol. 29, No.7, pp. 386-395, Jan. 2014

[4] M. A. Herran, J. R. Fischer, S. A. Gonzalez, M. G. Judewicz, and D. O. Carrica, "Adaptive dead-time compensation for grid-connected PWM inverters of single-stage PV systems," IEEE Trans. Power Electron., Vol. 28, No.6, pp. 2816-2825, Jun. 2013.

[5] T. L. M. Santos, D. Limon, J. E. Normey-Rico, and G. V. Raffo, "A dead-time compensation of constrained linear systems with bounded disturbances: output feedback case," IET Control Theory \& Applications, Vol. 27, No. 3, pp. 52-59, Jan. 2013.

[6] Z. Yao and L. Xiao, "Control of single-phase grid-connected inverters with nonlinear loads," IEEE Trans. Ind. Electron., Vol. 60, No.4, pp. 1384-1389, Apr. 2013.

[7] Z. Yao, "Two-switch dual-buck grid-connected inverter," in Proc. PEMCC, pp. 2182-2187, 2009.

[8] P. Sun, C. Liu, J.-S. Lai, and C.-L. Chen, "Cascade dual buck inverter with phase-shift control," IEEE Trans. Power Electron., Vol. 27, No. 4, pp. 2067-2077, Apr. 2012.

[9] P. Sun, C. Liu, J.-S. Lai, and C.-L. Chen, "Three-phase dual-buck inverter with unified pulsewidth modulation," IEEE Trans. Power Electron., Vol. 27, No. 3, pp. 1159-1167, Mar. 2012

[10] D. Jovcic, L. Zhang, and M. Hajian, "LCL VSC converter for high-power applications," IEEE Trans. Power Del., Vol. 28, No. 1, pp. 137-144, Jan. 2013.

[11] D. Dujic, G. K. Steinke, M. Bellini, M. Rahimo, L. Storasta, and J. K. Steinke, "Characterization of $6.5 \mathrm{kV}$ IGBTs for high-power medium-frequency soft-switched applications," IEEE Trans. Power Electron., Vol. 28, No.2, pp. 906-919, Feb. 2014.

[12] F. Z. Peng, J. Lai, and J. W. McKeever, "Study of rectifier diode loss model of the Flyback converter," in Proc PEDES, pp. 1-6, 2012 .

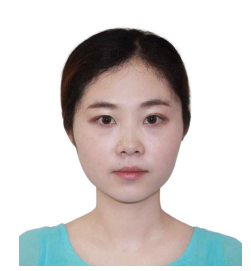

Xinxin Zheng was born in Anhui, China. She received her B.S. degree in electrical engineering from Nanjing University of Aeronautics and Astronautics, Nanjing, Jiangsu, in 2009. She is currently pursuing her $\mathrm{Ph} . \mathrm{D}$. degree in electrical engineering at the Aero-Power SCI Tech-Center, College of Automation Engineering, in the same institution.



Lan Xiao was born in Zhejiang, China. She received her B.S. and Ph.D. degrees in electrical engineering from Nanjing University of Aeronautics and Astronautics, Nanjing, Jiangsu, in 1993 and 1998, respectively. In 1999, she joined the faculty of the College of Automation Engineering, NUAA. She is currently a professor at the Aero-Power SCI Tech-Center in the same institution. She is the author and co-author of more than 50 technical papers in journals and conferences.

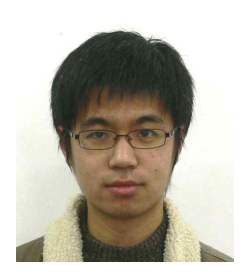

Yangtian Tian was born in Jiangsu, China. $\mathrm{He}$ received his M.S. degree in electrical engineering from Nanjing University of Aeronautics and Astronautics, Nanjing, Jiangsu, in 2013. 